\title{
KNOWLEDGE, PREVENTIVE PRACTICE, AND THE RISK OF DENGUE HEMORRHAGIC FEVER IN KUPANG, EAST NUSA TENGGARA
}

\author{
Ignasius Tangi Bupu'), Pius Weraman'), Rafael Paun²) \\ ${ }^{1)}$ Masters Program in Public Health, Universitas Nusa Cendana \\ ${ }^{2)}$ School of Health Polytechnics, Ministry of Health, Kupang
}

\begin{abstract}
Background: Dengue/dengue hemorrhagic fever (DHF) has been one of the most important resurgent tropical diseases in the past 17 years. Its incidence in East Nusa Tenggara has been increasing since 2011 to 2013. This study aimed to investigate the associations between knowledge, preventive practice, and the risk of dengue hemorrhagic fever in Kupang, East Nusa Tenggara.

Subjects and Method: This was a case control study conducted at 8 Puskesmas (Community Health Center) in Kupang, East Nusa Tenggara, Indonesia, from March to May 2016. A total of 72 subjects were selected for this study by fixed disease sampling, consisting of 36 DHF cases and 36 controls. The dependent variable was DHF. The independent variables were knowledge on DHF and DHF preventive practice including draining, hoarding, and burying. The data were collected by questionnaire and interview. The data were analyzed by a multiple logistic regression.

Results: Poor knowledge on DHF $(\mathrm{OR}=4.85 ; 95 \% \mathrm{CI}=1.62$ to $14.49 ; \mathrm{p}=0.005)$ and poor $\mathrm{DHF}$ preventive practice $(\mathrm{OR}=4.72 ; 95 \% \mathrm{CI}=1.60$ to $13.91 ; \mathrm{p}=0.005)$ were associated with an increased risk of DHF.

Conclusion: Poor knowledge on DHF and poor DHF preventive practice are associated with an increased risk of DHF.

Keywords: knowledge, preventive practice, dengue hemorrhagic fever.

\section{Correspondence:}

Ignasius Tangi Bupu. Masters Program in Public Health, Universitas Nusa Cendana, Indonesia. Email: ignasbupu@yahoo.co.id. Mobile: 085337698993.
\end{abstract}

